\title{
A CONSTRUÇÃO DE UM PROTÓTIPO DE ENERGIA SOLAR, EM SALA DE AULA
}

\author{
Myrna da Cunha ${ }^{1}$
}

Antonio Carlos de Miranda ${ }^{2}$

RESUMO: Para atingir seus objetivos, o ensino técnico tem que estar atento na busca de assuntos atuais e de novas tecnologias. Nesse sentido, esta investigação traz o tema energia solar em uma das disciplinas do curso Técnico em Segurança do Trabalho, visando explorá-lo em seus aspectos técnicos e científicos e, ao mesmo tempo, motivar os alunos na busca de novas soluções para os impactos ambientais existentes. Enfatiza-se também que as tecnologias podem se tornar viáveis se forem divulgadas de forma responsável e democrática.

Palavras-chave: Energia Solar. Impactos Ambientais. Educação Ambiental.

\footnotetext{
${ }^{1}$ Mestre em Ensino nas Ciências da Saúde e do Ambiente, Professora do Centro Federal de Educação Tecnológica Celso Suchow da Fonseca (CEFET/RJ). E-mail: myrna.cunha@globo.com

${ }^{2}$ Doutor (UNICAMP). Pesquisador do Programa de Mestrado em Ensino de Ciências. (UNIPLI). E-mail: mirantam@ig.com.br
} 


\section{INTRODUÇÃO}

Ao buscar soluções em relação aos impasses em relação ao uso da energia verificamos que um dos caminhos é a educação. Para isso, acreditamos ser necessário aprofundar os conteúdos, em sala de aula, de forma crítica e identificar, ao mesmo tempo, estratégias de ensino-aprendizagens motivadoras, que aliem a transformação dos alunos através da aprendizagem significativa, com conscientização de seu papel na sociedade. Nesse sentido, constrói-se as bases para que os alunos possam refletir e serem críticos em relação à ciência, às soluções tecnológicas e formas democráticas de acesso e a divulgação deste conhecimento. Cabe lembrar, em relação à aprendizagem significativa, o que dizem Moreira, Caballero e Rodrigues (1997, p. 8): "Mesmo que os significados cheguem ao aprendiz através de livros ou máquinas, por exemplo, ainda assim é através da interação social que ele/ela poderá assegurar-se que os significados que captou são os significados socialmente compartilhados em determinado contexto".

É importante frisar que um grande problema das questões ambientais é o grau de complexidade e a grande diversidade de propostas existentes. Somente a consciência ambiental não garante nenhuma ação transformadora, a busca da transformação tem que ser baseada no acesso democrático ao conhecimento, na atitude e na participação através do direito de tomar decisões que envolve o presente e o futuro dos cidadãos, apoiado em valores éticos e em justiça social.

Um grande obstáculo nesse desafio é o domínio dos países hegemônicos, às custas do empobrecimento cada vez maior dos demais países. Com isso, na maioria das vezes, o interesse econômico vai se sobrepor ao ambiental, deixando-o em segundo plano. Esse cenário se modifica, normalmente, quando os dois interesses (econômico e ambiental) estiverem apontando para o mesmo lado, como Sachs (2007) cita: 
É importante realizar esse debate, que, aliás, já tentamos iniciar há trinta e cinco anos, já em Estocolmo e após Estocolmo, mas trinta e cinco anos de discurso ambientalista não conseguiram fazer aquilo que seis meses de petróleo caro fizeram, ou seja, colocar realmente em pauta essa questão. (SACHS, 2007:31)

Essa última hipótese nos leva a um possível caminho: buscar soluções para as questões ambientais voltadas para a crise energética do mundo capitalista, claro que, de forma consciente, levando-se em conta o ambiente, o desenvolvimento sustentável, a ética e a justiça social.

Os problemas ambientais são muitos, e um dos mais preocupantes atualmente é o aquecimento global que, por isso, se tornou uma preocupação para as grandes nações. $O$ padrão de consumo das nações mais ricas representa uma das principais causas do aquecimento global, o que nos coloca a fundamental questão: "como fazer com que as nações desenvolvidas, a curto e médio prazo, reduzam seu consumo?".

Segundo Vianna (2007):

Não há conservação da natureza se a produção de energia se faz por meio da queima de fósseis (gás, petróleo e carvão mineral), responsável por mais de $90 \%$ da matriz energética mundial, produzindo $\mathrm{CO}_{2}$, aquecendo a Terra, mudando o clima e produzindo situações de redução de produção, seca e fome em várias partes do mundo. Sobretudo nos países mais pobres. Essa destruição pode ser reduzida, e as mudanças tecnológicas mais recentes apontam neste sentido: eficiência energética e economia de recursos naturais na produção material. (VIANNA, 2007:9)

Um dos caminhos para a redução do aquecimento global é a inibição da emissão de gases que aumentam o efeito estufa, e para isso pode-se produzir e usar energias alternativas. Nosso país já está na frente quando se trata de energias limpas e renováveis, o que precisamos agora é diversificar, investir em tecnologia para tornar as fontes de energia viáveis economicamente, e a tendência é que isso aconteça em curto espaço de tempo.

Outros países já estão utilizando energias renováveis e sua aceitação pelos consumidores está crescendo. A competição entre os diversos combustíveis e a redução 
do risco de ter só uma fonte de energia impulsionam o mercado na busca por soluções adequadas. Além disso, as metas de diminuição da emissão de carbono direcionam os países para as energias renováveis.

O próximo passo é saber quais são as energias renováveis adequadas para o crescimento sustentável do Brasil, investindo ou subsidiando as mesmas para que sua utilização seja viável.

\section{DESENVOLVIMENTO}

O tema central desta investigação envolve a energia solar, o desenvolvimento e a construção de um protótipo e como abordá-la no curso técnico de segurança do trabalho, através da disciplina Proteção Ambiental, que discute os impactos ambientais. Nosso objetivo, nesta investigação, é captar a luz para gerar energia elétrica e, para isso, é imprescindível o melhor posicionamento para que os módulos solares fotovoltaicos ${ }^{3}$ utilizem todos os componentes da radiação solar, ou seja, as radiações diretas, difusas e refletidas. Conforme enfatiza Dutra (2008):

De toda a radiação solar que chega às camadas superiores da atmosfera, apenas uma fração atinge a superfície terrestre, devido à reflexão e absorção dos raios solares pela atmosfera. Esta fração que atinge o solo é constituída por uma componente direta (ou de feixe) e por uma componente difusa. Notadamente, se a superfície receptora estiver inclinada com relação à horizontal, haverá uma terceira componente refletida pelo ambiente do entorno (solo, vegetação, obstáculos, terrenos rochosos, etc.). O coeficiente de reflexão destas superfícies é denominado de "albedo". (DUTRA, 2008:26)

A melhor forma para verificar a eficiência da captação de todos os componentes é através das medições. A quantidade de radiações existentes em um determinado lugar

\footnotetext{
${ }^{3}$ Esta tecnologia apoia-se no trabalho de Einstein publicado, em 1905, acerca do fenômeno 'efeito foto elétrico'.
} 
pode ser mensurada, se utilizarmos o piranômetro, um dos instrumentos que mede radiação solar e fornece a irradiância que é definida como potência incidente por unidade de área $(\mathrm{W} / \mathrm{m} 2)$. Para se obter a energia, multiplica-se a potência pela quantidade de horas utilizadas. Já a irradiação é definida como a energia por unidade de área $\left(\mathrm{Wh} / \mathrm{m}^{2}\right)$, ou seja, a multiplicação da irradiância pela quantidade de horas.

Hoje, já existem atlas mostrando o mapeamento solar de diversos países. consulta ao site do CRESESB verificamos que: "no Rio de Janeiro, no bairro do Maracanã (onde se situa a Escola cenário da pesquisa), por exemplo, a latitude é de $22^{\circ} 9^{\prime}$, e se colocarmos um módulo fotovoltaico com esta inclinação teríamos uma irradiação média diária anual de 4,64 kWh/m²/dia."

Após os esclarecimentos quanto à posição que se deve colocar o módulo fotovoltaico, deve-se entender como ele transforma energia solar em energia elétrica, mas, para isso, utiliza-se um semicondutor que ao ser exposto à luz provoca o surgimento de uma diferença de potencial (ddp) entre seus terminais de junção PN. Essas junções PN são equivalentes a diodo com grandes áreas.

A incidência de fótons (energia luminosa) na junção PN causa o aparecimento de cargas elétricas sob forma de pares elétrons-lacunas. Os elétrons gerados são movidos para o material $N$ (terminal negativo) e as lacunas, em direção ao material $P$ (terminal positivo), fazendo surgir uma ddp. Internamente os elétrons e as lacunas são mantidos afastados através de uma barreira de potencial existente e acabam se recombinando através de um circuito externo. Segundo Dutra (2008):

Existem na natureza materiais classificados como semicondutores, que se caracterizam por possuírem uma banda de valência totalmente preenchida por elétrons e uma banda de condução totalmente "vazia" à temperaturas muito baixas (DUTRA, 2008:30).

O semicondutor mais usado é o silício e os módulos fotovoltaicos tradicionais mais utilizados são de silício monocristalino (m-Si) e de silício policristalino ( $p$-Si). Mas, existem 
tecnologias mais recentes, como, por exemplo, os módulos compostos por: silício amorfo (a-Si), telureto de cadmio (CdTe), disseleneto de cobre e índio (CIS) e disseleneto de cobre, índio e gálio (CIGS).

Para escolher entre os diversos materiais existentes, em geral, decide-se pelo mais eficiente. Comercialmente, são fabricados produtos com eficiência de conversão conforme se segue: silício monocristalino de $12 \%$ a $15 \%$, silício policristalino de $11 \%$ a $14 \%$, silício amorfo de $8 \%$ a $10 \%$, telureto de cádmio de $7 \%$ a $10 \%$ e disseleneto de cobre, índio e gálio de $9 \%$ a $11 \%$.

Pode-se trabalhar com três tipos de sistemas fotovoltaicos: isoladamente, de forma híbrida ou conectado à rede. No isolado, a energia é armazenada; no híbrido, ela pode ser fornecida pelo sistema solar ou através de outra fonte paralela, como, por exemplo, o diesel; e no conectado à rede, a energia gerada é injetada na rede elétrica. Os sistemas fotovoltaicos isolados não possuem conexões com o sistema público de fornecimento de energia elétrica, por isso, normalmente são instalados em locais sem acesso à rede elétrica. Geram eletricidade e armazenam em baterias, o que os torna mais caros. São projetados para alimentar cargas de corrente contínua ou de corrente alternada. Atendem a consumidores individuais, vários consumidores ou cargas especiais.

Já nos sistemas fotovoltaicos conectados à rede, a energia é gerada e injetada na rede elétrica. Portanto, não necessitam baterias para armazenar energia, reduzindo os custos de geração, e podem ser instalados integrados a edificações, proporcionando geração distribuída, ou instalados em locais amplos, atuando como uma central geradora.

Uma primeira questão apresenta-se. Como dimensionar um sistema fotovoltaico? Inicialmente, obtêm-se os dados de irradiação para o local desejado, a seguir, faz-se a estimativa da geração de energia elétrica em cada mês e da geração anual, especificando o inversor para o sistema fotovoltaico conectado à rede (SFVCR) e os módulos fotovoltaicos.

Para se obter os dados de irradiação de um local, utiliza-se o banco de dados do Potencial Energético Solar SUNDATA, do CRESESB, disponível na internet. 
Considerando que o local da instalação (cenário da pesquisa) é o CEFET/RJ, localizado no bairro do Maracanã, no Rio de Janeiro, e que a latitude nesse local é de aproximadamente $23^{\circ}$, se obtém uma irradiação solar total média $\left(\mathrm{H}_{\text {TOT }}\right)$ de 4,22 $\mathrm{kW} / \mathrm{m}^{2} / \mathrm{dia}$.

Em seguida, deve-se fazer um quadro de cargas, dimensionando a potência a ser instalada e seu tempo de utilização, desse modo, obtém-se a energia que será consumida. Como exemplo, apresentamos o quadro de cargas da iluminação do jardim do Curso de Segurança do Trabalho, do CEFET/RJ Maracanã, que é composto por 10 postes, cada um com uma lâmpada de led de 3,6 W.

\begin{tabular}{|c|c|c|c|c|c|}
\hline Carga & $\begin{array}{c}\text { Potência } \\
(\mathrm{W})\end{array}$ & $\begin{array}{c}\text { Tensão } \\
(\mathrm{V})\end{array}$ & $\begin{array}{c}\text { Corrente } \\
(\mathrm{A})\end{array}$ & $\begin{array}{c}\text { Tempo } \\
(\mathrm{h})\end{array}$ & $\begin{array}{c}\text { Energia } \\
(\mathrm{Wh} / \mathrm{dia})\end{array}$ \\
\hline Led & 3,6 & 12 & 0,3 & 4 & 14,4 \\
\hline Led & 3,6 & 12 & 0,3 & 4 & 14,4 \\
\hline Led & 3,6 & 12 & 0,3 & 4 & 14,4 \\
\hline Led & 3,6 & 12 & 0,3 & 4 & 14,4 \\
\hline Led & 3,6 & 12 & 0,3 & 4 & 14,4 \\
\hline Led & 3,6 & 12 & 0,3 & 4 & 14,4 \\
\hline Led & 3,6 & 12 & 0,3 & 4 & 14,4 \\
\hline Led & 3,6 & 12 & 0,3 & 4 & 14,4 \\
\hline Led & 3,6 & 12 & 0,3 & 4 & 14,4 \\
\hline Led & 3,6 & 12 & 0,3 & 4 & 14,4 \\
\hline Total & & & & & 144,0 \\
\hline
\end{tabular}

Tabela1 - Quadro de carga da futura iluminação do jardim do CEFET/RJ

Para dimensionar o Painel Fotovoltaico, utilizaremos a fórmula abaixo:

$$
P_{F V}=E \times G / H_{T O T} \times P R
$$

Onde:

$P_{F V}$ - Potência Instalada $(\mathrm{Wp})$ 
$\mathrm{E}$ - Energia gerada $(\mathrm{Wh})$

G - Irradiância na condição STC $\left(1000 \mathrm{~W} / \mathrm{m}^{2}\right)$

$\mathrm{H}_{\text {TOT }}$ I Irradiação total diária $\left(\mathrm{W} / \mathrm{m}^{2}\right)$

PR - Taxa de desempenho do SFVCR $(\sim 0,8)$

Potência do Painel Fotovoltaico para 10 lâmpadas Led de 3,6 W:

$$
\begin{gathered}
P_{F V}=E \times G / H_{T O T} \times P R \\
P_{F V}=144 \times 1000 / 4,22 \times 1000 \times 0,8
\end{gathered}
$$

$$
\mathrm{P}_{\mathrm{FV}}=42,7 \mathrm{~W}
$$

A partir desse valor consulta-se o catálogo de fornecedores para escolher o melhor módulo fotovoltaico, que tenha uma potência superior ao valor acima. Decide-se, então, pelo módulo solar poli cristalino da Kyocera, com potência nominal de $135 \mathrm{~W}$, corrente nominal de 7,63 A, corrente de curto circuito de 8,37A, tensão nominal de $17,7 \mathrm{~V}$, tensão de circuito aberto de 22,1A, dimensões de $1500 \times 668 \times 46 \mathrm{~mm}$, peso de $12,5 \mathrm{~kg}$, certificado do INMETRO e custo de $\mathrm{R} \$ 900,00$.

Através desse exemplo, verifica-se que não existe dificuldade para o dimensionamento dos sistemas fotovoltaicos, bem como ele se torna mais simples, pois as empresas que comercializam os produtos fazem esses cálculos, sendo necessário somente saber qual é a carga existente.

O traçado metodológico desta investigação pode ser identificado, em uma primeira etapa, como uma pesquisa bibliográfica. A seguir, como experimental com procedimentos quantitativos expressos por dados envolvendo medidas, valores e variáveis. Como sujeitos da pesquisa, envolvidos na montagem e nas medições, escolheu-se a turma do segundo período por estar na série correspondente à disciplina de Proteção Ambiental. Com vinte e quatro estudantes, sendo dezessete alunas e sete alunos, na faixa etária 
entre 15 e 20 anos, cursando o ensino médio concomitantemente ao ensino técnico, no CEFET, RJ.

Em um primeiro momento, os estudantes fizeram um levantamento bibliográfico acerca do tema energia, na biblioteca da Escola e através de artigos, revistas, livros. Com isso, visou-se a aquisição de novos conhecimentos, pela introdução e divulgação de temas atuais e pela motivação que esses temas provocam nos alunos. Esses conhecimentos objetivaram entender os impactos ambientais das três maiores fontes de energia utilizadas no mundo (petróleo, carvão e gás natural) e o quanto provocam de danos ao ambiente. Em contrapartida, analisaram-se outras fontes de energia, as renováveis e limpas, que não provocam tantos danos ao ambiente e que reduziriam muito os impactos ambientais provocados pelas não renováveis através de novas tecnologias.

Cabe esclarecer que esta etapa da pesquisa visava a construção de um conteúdo pelos alunos e, ao mesmo tempo, como desenvolvê-lo em uma turma do curso técnico de segurança do trabalho, na disciplina de Proteção Ambiental. É importante destacar essa disciplina em sua ementa aborda muitos temas voltados para o controle e/ou a eliminação dos impactos ambientais, as legislações existentes e a gestão desses impactos, no entanto, não aprofunda a questão energética nem tem como objetivo a construção de um protótipo.

Ao mostrar os impactos ambientais e a tentativa de promover a reflexão quanto às soluções alternativas para reduzi-los, foi mais fácil discutir sobre energias não renováveis e renováveis. A seguir, foram ministradas aulas sobre energias renováveis e não renováveis. Em seguida, discutindo-se a energia solar, suas vantagens e desvantagens; como ocorre a transformação em eletricidade; que processo era utilizado para ocorrer tal transformação; que tipo de material deveria ser utilizado, se os tradicionais e/ou as novas tecnologias; e, por fim, como poderia ser calculado um pequeno sistema de energia elétrica.

Durante a aula, observamos que a turma ficou muito motivada e a maioria dos alunos demonstrou interesse pelo tema. Muitas questões surgiram, entre outras: Não é 
possível a instalação do sistema em suas casas? Qual o custo de instalação? Se existiam empresas instaladoras no Brasil? Que tipo de carga pode ser utilizado nesse sistema? Se existia legislação pertinente para a utilização dessa fonte de energia?

A discussão serviu para aprofundar os conhecimentos dos alunos sobre a importância de divulgarmos a energia solar, fazendo com que cada vez mais pessoas dominem o tema e possam exigir políticas públicas que popularizem a sua utilização, além de mecanismos para subsidiá-la, permitindo que o processo de seu desenvolvimento e utilização ocorram com maior rapidez, desse modo, tornando o seu uso viável não só ambientalmente, mas também economicamente.

Em princípio, os alunos "aprenderam" o conteúdo transmitido, mas, uma semana depois, quando se aplicou um teste sobre os diversos assuntos da disciplina e os mesmos escreveram sobre energia solar, verificou-se que o conhecimento ainda não estava consolidado.

Após uma discussão em sala de aula acerca da transformação de energia solar em elétrica, teve início o planejamento e a construção do protótipo. Com objetivo central de demonstrar a transformação de energia solar em eletricidades, foi composto por um módulo fotovoltaico de $5 \mathrm{~W}$ (Figuras 1), construído de células fotovoltaicas, essencialmente junções PN, equivalentes a diodos semicondutores de silício, de grande área; de um cooler com lâmpadas de leds com carga total de 3,6 W (Figura 2); de fios isolados de $2,5 \mathrm{~mm}^{2}$ e de uma caixa com tampa com um interruptor e uma tomada (Figura 3), para podermos medir a tensão elétrica do módulo com carga ou sem carga. E para fazer a medição da corrente elétrica utilizou-se um amperímetro (Figura 4).

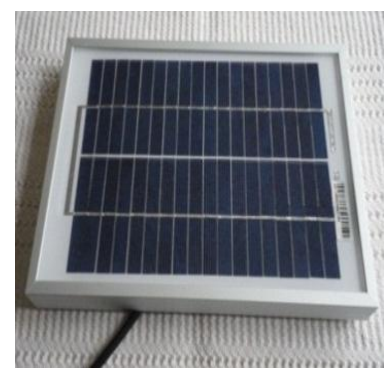

Fig. 1 - Módulo fotovoltaico

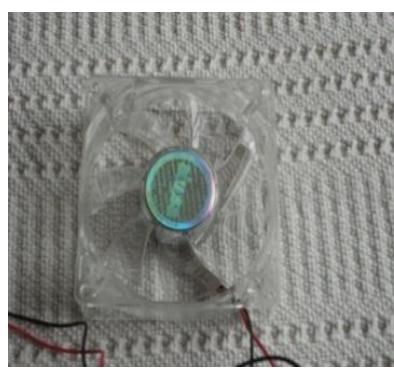

Fig. 2 - Cooler (ventoinha)

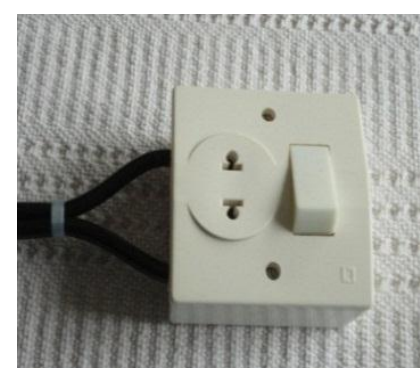

Fig. 3 - Caixa com tomada

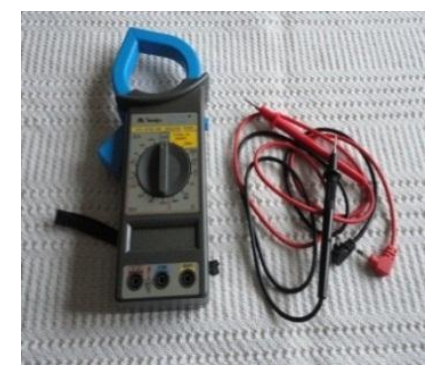

Fig. 4 - Amperímetro

VIII Fórum Ambiental da Alta Paulista, v. 8, n. 6, 2012, p. 60-73. 
A construção do protótipo serviu também para que os alunos pudessem entender como acontecia a transformação de energia solar em eletricidade, ou seja, como a luz captada (energia solar) se transformava em ddp (diferença de potencial). Com o protótipo, ficou bem mais fácil demonstrar que a grade metálica na superfície frontal do módulo fotovoltaico coleta os elétrons gerados (polo negativo), e que na superfície posterior há um contato metálico destinado a retornar os elétrons que deixaram a superfície frontal (polo positivo).

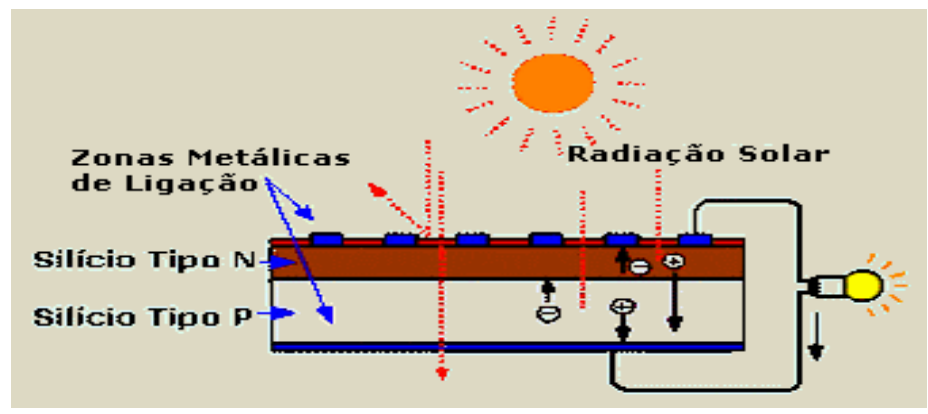

Fonte:http://apenergiasrenovaveis.wordpress.com/solar/energia-solar-fotovoltaica-como-se-produz/

Visualmente, através do protótipo, também foi possível mostrar de que material era feito o módulo fotovoltaico, uma tecnologia tradicional, o poli cristalino ( $\mathrm{p}-\mathrm{Si}$ ), com custo mais acessível em relação ao mono cristalino (m-Si), e boa eficiência na conversão.

Para demonstrar o objetivo central da construção do protótipo, comprovou-se, através de medições, a transformação de energia solar em eletricidade. Então, tais medições ocorreram com o protótipo no jardim do bloco I no CEFET/RJ, unidade do Maracanã, durante duas semanas, em dois horários diferentes, 09 e 14 horas.

Os testes foram realizados entre os dias 12 e 22 de março de 2012, e nos dois horários a incidência solar foi considerada adequada ao experimento. Foram feitas medições com e sem incidência solar, com o módulo na horizontal, inclinado, com e sem carga. A tabela 1, a seguir, apresenta algumas das medições descritas acima: 


\begin{tabular}{|c|c|c|c|c|}
\hline Data & $\begin{array}{c}\text { Tensão em } \\
\text { (V) } \\
\text { as 09:00 h } \\
\text { com sol }\end{array}$ & $\begin{array}{c}\text { Tensão em } \\
\text { (V) } \\
\text { as 09:00 h } \\
\text { sem sol }\end{array}$ & $\begin{array}{c}\text { Tensão em } \\
\text { (V) } \\
\text { as 14:00 h } \\
\text { com sol }\end{array}$ & $\begin{array}{c}\text { Tensão em } \\
\text { (V) } \\
\text { as 14:00 h } \\
\text { sem sol }\end{array}$ \\
\hline $\begin{array}{c}12 / 03 / \\
2012\end{array}$ & $14,1 \mathrm{~V}$ & $6 \mathrm{~V}$ & $13,1 \mathrm{~V}$ & $5,8 \mathrm{~V}$ \\
\hline $\begin{array}{c}13 / 03 / \\
2012\end{array}$ & $14,4 \mathrm{~V}$ & $6,5 \mathrm{~V}$ & $13,8 \mathrm{~V}$ & $6,0 \mathrm{~V}$ \\
\hline $\begin{array}{c}14 / 03 / \\
2012\end{array}$ & $14 \mathrm{~V}$ & $5,8 \mathrm{~V}$ & $13,2 \mathrm{~V}$ & $5,4 \mathrm{~V}$ \\
\hline $\begin{array}{c}15 / 03 / \\
2012\end{array}$ & $13,8 \mathrm{~V}$ & $6,2 \mathrm{~V}$ & $13,5 \mathrm{~V}$ & $6,0 \mathrm{~V}$ \\
\hline $\begin{array}{c}16 / 03 / \\
2012\end{array}$ & $14,5 \mathrm{~V}$ & $6,1 \mathrm{~V}$ & $13,7 \mathrm{~V}$ & $5,8 \mathrm{~V}$ \\
\hline $\begin{array}{c}19 / 03 / \\
2012\end{array}$ & $13,6 \mathrm{~V}$ & $6,4 \mathrm{~V}$ & $13,4 \mathrm{~V}$ & $5,4 \mathrm{~V}$ \\
\hline $\begin{array}{c}20 / 03 / \\
2012\end{array}$ & $14,5 \mathrm{~V}$ & $5,4, \mathrm{~V}$ & $14,0 \mathrm{~V}$ & $5,0, V$ \\
\hline $\begin{array}{c}21 / 03 / \\
2012 \\
\end{array}$ & $13,8 \mathrm{~V}$ & $6,3 \mathrm{~V}$ & $13,5 \mathrm{~V}$ & $6,0 \mathrm{~V}$ \\
\hline $\begin{array}{c}22 / 03 / \\
2012\end{array}$ & $14,6 \mathrm{~V}$ & $6,6 \mathrm{~V}$ & $13,6 \mathrm{~V}$ & $6,1 \mathrm{~V}$ \\
\hline
\end{tabular}

Tabela 1 - Medição de tensão com e sem sol

Através das medições acima, comprova-se que nos locais com incidência solar a transformação de energia solar em eletricidade aconteceu de acordo com o esperado, obteve-se uma boa tensão que fez o cooler funcionar, ao contrário dos locais sem incidência solar, pois o módulo fotovoltaico precisa de uma tensão de $12 \mathrm{~V}$ a 17,56 V. Além disso, tanto de manhã como à tarde a incidência solar foi satisfatória. Também são demonstrados os valores de tensão de acordo com horário e posição do módulo. A tensão do módulo era melhor com uma inclinação do que na horizontal, pois na primeira posição o módulo conseguia captar as três componentes da radiação solar, a direta, a difusa e a refletida. Já na posição horizontal, ele só conseguia captar as componentes direta e difusa.

Com a comprovação de que o protótipo conseguia demonstrar visualmente, através de medições, a transformação de energia solar em energia elétrica, concluiu-se que o mesmo estava pronto para ser apresentado na aula prática.

No dia 02/04/2012 houve a primeira aula prática sobre energia solar do curso técnico de segurança do trabalho. Nesse dia, a turma foi dividida em cinco grupos, quatro grupos com cinco alunos e um grupo com quatro alunos. Para cada grupo foi ministrada 
uma aula prática com o protótipo de energia solar e, durante a demonstração, os alunos podiam manuseá-lo; verificar qual o material utilizado; medir a tensão gerada a partir do módulo fotovoltaico; verificar se a inclinação influenciava na tensão; qual era a melhor posição para colocar o módulo; e colocar e retirar a carga (cooler com as lâmpadas "leds") através do manuseio do interruptor.

Mas, o mais importante é que os alunos participaram da construção de um conteúdo em relação à transformação de energia solar em eletricidade de uma forma análoga, como ocorreria em um sistema de energia solar voltado para uma casa e/ou edifício. Nesse sentido, cabe lembrar que "a aprendizagem significativa, por definição, envolve aquisição/construção de significados. É no curso da aprendizagem significativa que o significado lógico dos materiais de aprendizagem se transforma em significado psicológico para o aprendiz." (MOREIRA, 1997:9)

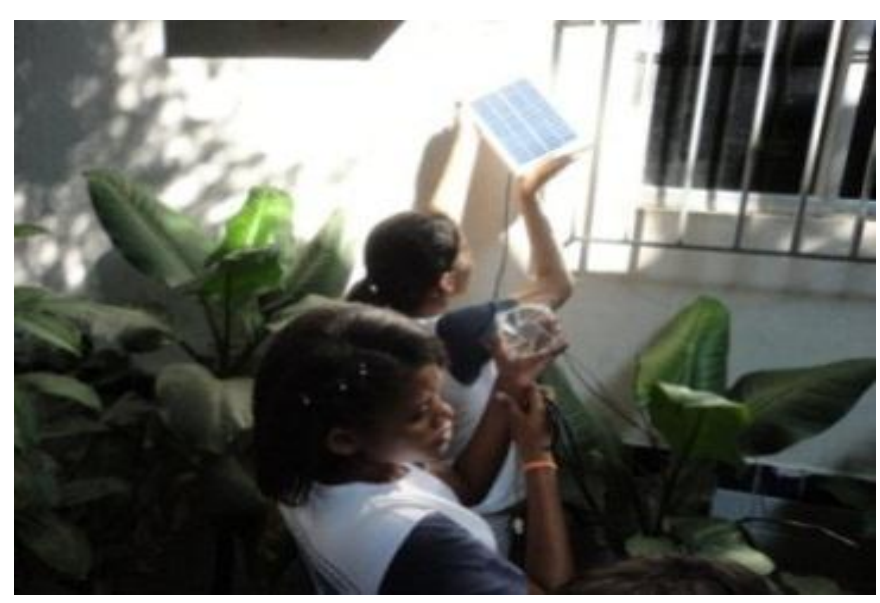

Fig. 5 - Os alunos com o Módulo fotovoltaico

\section{CONCLUSÃO}

É importante destacar que através dessa experiência o aluno passou a assimilar o conteúdo que envolve a transformação da energia solar em energia elétrica, e 
principalmente, a verificar que é um processo relativamente simples de construção e de medidas (embora o fenômeno físico seja complexo) e, portanto, viável de ser aplicado, em sala de aula. Por outro lado, permitiu a possibilidade da introdução dos conceitos de energia solar, através da discussão dos impactos ambientais produzidos pelas fontes de energias existentes, até então não consideradas na disciplina de Proteção Ambiental do curso de técnico de segurança do trabalho. A investigação, nesse sentido, contribuiu para que a ementa da disciplina Proteção Ambiental incorporasse o tema energia solar e a construção do protótipo, que, como percebemos, possuem uma grande capacidade de motivar os alunos na área tecnológica, além de demostrar as possibilidades energéticas alternativas, que podem ser abordadas, em sala de aula.

\section{REFERÊNCIAS BIBLIOGRÁFICAS}

DUTRA, R. M. et al. Manual de engenharia para sistemas fotovoltaicos. Rio de Janeiro: CRESESB, 2008.

CHIARAVALLOTI, R. M.; PÁDUA, C. V. Escolhas sustentáveis: discutindo biodiversidade, uso da terra, água e aquecimento global. São Paulo: Urbana, 2011.

GALDINO, M. A. et al. Coletânea de artigos: energias solar e eólica. Volume 02 . Rio de Janeiro: CRESESB, 2005.

GRIPPI, S. O gás natural e a matriz energética nacional. Rio de Janeiro: Interciência, 2009.

MOREIRA, M.A., CABALLERO, M.C. e RODRÍGUEZ, M.L. (orgs.) (1997). Actas del Encuentro Internacional sobre el Aprendizaje Significativo. Burgos, España. pp. 1944.

NGÔ, C. Energia: motor da humanidade: tradução de Constância Egrejas. São Paulo: Senac São Paulo, 2011.

SACHS, Ignacy et al. Dilemas e desafios do desenvolvimento sustentável no Brasil. Rio de Janeiro: Garamond, 2007.

VIANNA, João Nildo et al. Dilemas e desafios do desenvolvimento sustentável no Brasil. Rio de Janeiro: Garamond, 2007. 